\title{
Pioglitazone does not modify ANP levels of type 2 diabetic patients
}

\author{
Stefano Benedini ${ }^{1,2 *}$, Paolo Villa ${ }^{3}$, Livio Luzi ${ }^{1,2}$, Maurizio Bevilacqua ${ }^{3}$ \\ ${ }^{1}$ Metabolism Research Center, Policlinico San Donato IRCCS San Donato Milanese, Milan, Italy \\ ${ }^{2}$ Dipartimento di Scienze Biomediche per la Salute, University of Milan, Milan, Italy \\ ${ }^{3}$ Endocrinology and Diabetes Unit, Department of Medicine, Luigi Sacco (Vialba), University of Milan, Milan, Italy \\ Email: ${ }^{*}$ stefano.benedini@unimi.it
}

Received 23 August 2012; revised 27 September 2012; accepted 2 October 2012

\begin{abstract}
Background: The atrial natriuretic peptide (ANP) regulates fluid volume redistribution between heart and the pulmonary vessels. In diabetic patients the physiological action of ANP appears to be seriously altered. Methods: 12 subjects (gender $6 \mathrm{M} / 6 \mathrm{~F}$, age $47 \pm$ 2 years, BMI $29.1 \pm 0.1 \mathrm{~kg} / \mathrm{m}^{2}$ ), with type 2 diabetes and under stable conditions, were studied after one month of pioglitazione treatment $(30 \mathrm{mg} / \mathrm{die})$ by means of isotonic blood volume expansion. Results: After one month of pioglitazone treatment the metabolic profile of the subjects improved (decrease diastolic blood pressure: $p=0.05$, total cholesterol: $p=$ 0.01, triglycerides: $p=0.03$ and blood glucose: $p=$ 0.01 ) as the expansion of their plasma volume was found associated with the decrease of hematocrit $(p<$ 0.05). The statistical comparison before versus after pioglitazone showed a significant decrease in the basal aldosterone levels post-treatment $(p<0.04)$. Nonetheless ANP plasma levels were similar before and after therapy. Conclusions: The inappropriately high concentrations of ANP induced by hyperglycemia and the abnormal responses to a physiological stimulus like an isotonic blood volume expansion are not reverted by one month of pioglitazone. This is in contrast with the brisk improvement of the metabolic profile seen for the same period of treatment. ANP secretion is modified by fluid load in diabetic patients. This anomaly is not reverted by pioglitazone.
\end{abstract}

Keywords: Atrial Natriuretic Peptide; Pioglitazone; Insulin Resistance; Blood Glucose

\section{INTRODUCTION}

The Atrial Natriuretic Peptide (ANP) is a hormone play-

${ }^{*}$ Corresponding author. ing a major role in fluid homeostasis by protecting the cardiovascular system against volume overload. This polypeptide is released by the myocardium into the circulation in response to atrial distension. ANP release is enhanced during hypertonic saline infusion followed by spontaneous water drinking, due to the increase of atrial pressure [1] and as a consequence of the atrial stretch during an expansion of the intravascular fluid compartment [2,3]. Acute infusion of insulin [3,4], glucose load [5], and hyperglycemia [6] are able to increase the plasma levels of ANP. The infusion of physiological doses of ANP does not modify renal extraction nor cause vasodilatation, although it elicits an increase in capillary filtration [7].

In heart transplant recipients high levels of ANP were found after surgery $[8,9]$, thereafter normalized to physiological levels [10] or, according to some other reports [11], remained persistently high values. We previously showed that diabetic heart transplanted patients, had elevated plasma ANP concentrations similarly to the not transplanted diabetic patients. In contrast, non diabetic patients had normal plasma ANP levels. Therefore, chronic hyperglycemia seemed to be the main factor responsible of the increase of ANP concentration [12].

Type 2 diabetes itself is a pathologic condition characterized by volumetric expansion, associated with alteration of sympathetic system as well as peripheral neuropathy [13]. As a consequence of this, in type 2 diabetic patients (T2DP), alterations of cardio-pulmonary afferences [14], and of renin-angiotensin axis [15] along with irregular secretion of atrial natriuretic peptide $[16,17]$ were described, underlying a possible decrease of density and sensibility of peripheral receptors [18].

The sodium retention effect of thiazolidinediones (TZD) is very relevant in T2DP.

In isolated myocytes TZD was able to decrease the secretion of ANP $[19,20]$. Nonetheless, it is currently not clear whether TZD have a direct effect on endocrine mechanisms regulating the water-salt balance in humans. 
Pioglitazone is a thiazolidinedione compound that acts as a peroxisome proliferator activating receptor (PPAR)$\gamma$ agonist with potential benefits on insulin resistance. Pioglitazone [( \pm )-5-[[4-[2-(5-ethyl-2-pyridinyl) ethoxy] phenyl] methyl]-2,4-] thiazolidinedione monohydrochloride contains one asymmetric carbon, and the compound is synthesized and used as the racemic mixture. This drug is an antihyperglycaemic agent that, in the patients with insulin resistance, increases hepatic and peripheral insulin sensitivity, due to inhibition of hepatic gluconeogenesis and to increase peripheral and splanchnic glucose uptake [21].

The present work was undertaken to assess the effect of one month of pioglitazone treatment on plasma ANP concentration and the related metabolic profile in this cohort of diabetic individuals.

Considering the effects of pioglitazone on plasma renin activity and plasma aldosterone, the ability of PPAR $\gamma$ agonists to increase renal sodium reabsorption is most likely due to the activation of the renin-aldosterone system. Moreover, pioglitazone was proved to have a significant effect on renin secretion and renal sodium handling which may contribute to the development of peripheral edema in some patients $[22,23]$. The present study aimed at investigating a putative dissociation between a shortterm pioglitazone treatment and fluid homeostasis in T2DP.

\section{MATERIALS AND METHODS}

\subsection{Subjects}

Twelve subjects affected by type 2 diabetes mellitus ( 6 men/ 6 women, caucasians, age $47 \pm 2$ years, duration of diabetes $8 \pm 2$ years, weight $64.2 \pm 2.5 \mathrm{Kg}$, BMI $29.1 \pm$ $0.1 \mathrm{Kg} / \mathrm{m}^{2}$ ) under stable conditions in the previous 6 months, were selected for this study among the population of patients treated at the Endocrinology Unit of Ospedale L. Sacco in Milan (Italy). A medical history, physical examination, and biochemical laboratory screening tests were obtained to exclude patients with major gastrointestinal, cardiovascular, neuralgic or infectious disorders. All patients were on oral hypoglycemic agent. The subjects were instructed on the purpose, benefits and risks of the study and gave their written consent in accordance with protocols approved by the Institutional Ethical Committee.

\subsection{Experimental Protocol}

In the two weeks preceding the study all the subjects assumed an isocaloric diet containing at least $250 \mathrm{~g}$ of carbohydrates and $70-90 \mathrm{~g}$ of proteins per day. On day 1 , the patients were admitted to hospital at $5 \mathrm{pm}$ for the isotonic saline infusion $(2000 \mathrm{cc}$ of $\mathrm{NaCl} 0.9 \%$ for 2 hours). A teflon catheter was inserted into an antecubital vein for blood sampling and samples were obtained for blood cell count, renin, aldosterone, vasopressin, ANP, epinephrine and norepinephrine, concentrations, at baseline and during sampling at $30 \mathrm{~min}$ intervals up to 120 min (basal, 30, 60, 90, 120 minutes). A basal fasting blood sample for lipid profile (apo-A1, apo-B total, and uric acid) and blood glucose was drawn before starting the infusion. After blood pressure and heart rate were measured at 60 and $120 \mathrm{~min}$ after starting the saline infusion. On day 2, after one month of pioglitazone treatment $(30 \mathrm{mg} /$ day) the patients have undergone the same procedure of day 1 .

\subsection{Analytical Methods}

All blood samples were placed on ice until plasma or serum was separated by centrifugation at $4^{\circ} \mathrm{C}$ (within 1.5 hours from sampling). All plasma and serum aliquots were frozen at $-60^{\circ} \mathrm{C}$ until later analysis. Aliquots of blood for measurement of ANP were collected in tubes containing EDTA plus Trasylol; all the samples were kept in ice and the plasma prepared by centrifugation at $4^{\circ} \mathrm{C}$, within 1.5 hours from sampling. Plasma ANP was assessed by a specific Radio Immuno Assay with kits supplied by Nichols (Nichols Institute Diagnostic, Ca, USA). The plasma osmolality was determined with the freezing point depression method (Fiske osmometer by Fiske Co., Burlington, Ma, USA). Plasma glucose was measured with a Beckman glucose analyzer (glucose oxidase).

The uric acid clearance (CIUr) is a good circulating marker of extracellular fluid; this marker increases in case of a water overload [24,25]. To calculate the urinary clearance of uric acid, we used the equation:

$$
\mathrm{ClUr}=[\mathrm{Ur}(\mathrm{u})] /[\mathrm{Ur}(\mathrm{s})] \times \text { Urinary volume } 24 \mathrm{~h} / 1440
$$

where $\operatorname{Ur}(\mathrm{u})$ is the urinary uric acid concentration and $\mathrm{Ur}(\mathrm{s})$ is the seric uric acid concentration.

The variation of plasma volume $(\Delta \mathrm{Vol})$ was calculated by using the value of hemoglobin $(\mathrm{Hb})$ and Hematocrit $(\mathrm{Ht})$ according to the following equation:

$\Delta \mathrm{Vol}=\{(\mathrm{Hb} 1 / \mathrm{Hb} 2) \times[(100-\mathrm{Ht} 2) /(100-\mathrm{Ht} 1)]-1\} \times 100$

Renin, aldosterone, vasopressin were measured by commercial Radio Immuno Assay kits. Epinephrine and Norepinephrine were measured by HPLC as previously described [12]. Standard laboratory methods were used to assess blood cell count. Total cholesterol and triglycerides were determined in serum using manual enzymatic methods (Boehringer AG, Marburg, Germany). At the same time, high-density lipoprotein (HDL) cholesterol was determined enzymatically after precipitation of apolipoprotein B (ApoB) with dextran sulfate. Low-density lipoprotein (LDL) cholesterol was calculated ac- 
cording to Friedewald's equation. ApoB and ApoA1 were measured at weeks 0,8 , and 20 from the beginning of the treatment, using commercially available radio-immuno-diffusion methods.

\subsection{Statistical Analysis}

Data are expressed as means $\pm \mathrm{SE}$. Comparison between before and after one month of pioglitazone treatment were performed with the Student's t test for paired data (a p-value less than 0.05 was considered statistically significant).

\section{RESULTS}

No adverse events were observed during administration of pioglitazone. Clinical, anthropometrics and laboratory data are summarized in Table 1. No statistical difference was evident for any anthropometric data after one month of therapy. In contrast, diastolic blood pressure was lower after one month pioglitazone treatment.

Our study confirmed the decrease of total cholesterol, Apo B and triglycerides levels after one month treatment with pioglitazone.

Plasma volume expansion was also confirmed and outlined by the significant reduction of hematocrit $(\mathrm{p}<0.05$ with respect to pre-treatment period).

Volume expansion was similar in the basal condition at the baseline and after therapy as indicated after 120 minutes from the infusion of 2 liter of $0.9 \% \mathrm{NaCl}$ solution. Table 2 shows hormone responses to test volume expansion before and after therapy. Plasma volume expansion after therapy with pioglitazone induced a decrease of plasma aldosterone during infusion of 2 liter of $0.9 \% \mathrm{NaCl}$ solution ( $\mathrm{p}<0.05$ at 60', 90', 120' vs basal). The decrease of vasopressin and renin plasma was evident about before therapy after volume expansion (at 30', $60^{\prime}, 90^{\prime}, 120^{\prime}$ ) and the decrease after therapy was present only at the end of study (90' and 120').

In the pre treatment condition, during saline infusion, we observed a trend to decrease of plasma norepinephrine and epinephrine (Table 3).

In contrast, ANP concentration resulted to be significantly increased with respect to the basal condition, after 2 hours of saline infusion test (Figure 1).

After one month treatment with pioglitazone we detected a significant decrease of aldosterone at each time point during the isotonic test $(\mathrm{p}<0.04$ vs pre-treatment values), whereas ANP plasma levels were similar to the prior treatment condition regardless of therapy $(p=n s)$.

Epinephrine and norepinephine did not decrease after two hours of saline infusion after therapy with pioglitazone (Table 3). After 120 minutes of saline infusion both epinephrine and norepinephine showed higher levels in comparison with the prior condition.
Table 1. Clinical and laboratory characteristics of study subjects before and after therapy with pioglitazone.

\begin{tabular}{|c|c|c|}
\hline & PRE pioglitazone & POST pioglitazone \\
\hline BMI $\left(\mathrm{kg} / \mathrm{m}^{2}\right)$ & $29.15 \pm 0.89$ & $29.09 \pm 0.86$ \\
\hline Waist (cm) & $104.7 \pm 2.8$ & $104.3 \pm 2.7$ \\
\hline Blood glucose (mmol/l) & $8.55 \pm 0.19$ & $7.51 \pm 0.13^{*}$ \\
\hline $\begin{array}{c}\text { Systolic blood } \\
\text { pressure (mmHg) }\end{array}$ & $127.5 \pm 3.6$ & $124.0 \pm 1.9$ \\
\hline $\begin{array}{l}\text { Diastolic blood } \\
\text { pressure (mmHg) }\end{array}$ & $81.5 \pm 2.4$ & $77.0 \pm 1.7^{*}$ \\
\hline Heart rate (bpm) & $72 \pm 1.3$ & $70.4 \pm 2.3$ \\
\hline $\begin{array}{l}\text { Uric acid clearance } \\
(\mathrm{ml} / \mathrm{min})\end{array}$ & $6.32 \pm 1.63$ & $8.77 \pm 1.57^{*}$ \\
\hline Hct (\%) & $40.13 \pm 0.97$ & $38.39 \pm 1.14^{*}$ \\
\hline $\begin{array}{l}\text { Total Cholesterol } \\
\text { (mmol/l) }\end{array}$ & $4.62 \pm 0.20$ & $4.30 \pm 0.18^{*}$ \\
\hline HDL-C (mmol/l) & $1.29 \pm 0.08$ & $1.29 \pm 0.07$ \\
\hline LDL-C (mmol/l) & $2.50 \pm 0.20$ & $2.39 \pm 0.20$ \\
\hline Triglycerides (mmol/l) & $1.79 \pm 0.34$ & $1.34 \pm 0.20^{*}$ \\
\hline Apo A1 (mg/dl) & $117.5 \pm 4.5$ & $116.0 \pm 4.6$ \\
\hline Apo B (mg/dl) & $95.7 \pm 5.1$ & $88.1 \pm 5.3^{*}$ \\
\hline
\end{tabular}

${ }^{*} \mathrm{p} \leq 0.05$ vs pre.

Table 2. Plasma renin activity, plasmatic aldosterone, plasmatic vasopressin during volume expansion before and after therapy.

\begin{tabular}{|c|c|c|}
\hline $\begin{array}{c}\text { Plasma renin } \\
\text { activity }(\mathrm{ng} / \mathrm{l} / \mathrm{s})\end{array}$ & PRE pioglitazone & POST pioglitazone \\
\hline $\mathbf{t}+\mathbf{0}$ & $1.05 \pm 0.34$ & $0.84 \pm 0.39$ \\
\hline $\mathbf{t}+\mathbf{3 0}$ & $0.86 \pm 0.35$ & $0.77 \pm 0.30$ \\
\hline$t+60$ & $0.79 \pm 0.36$ & $0.72 \pm 0.25$ \\
\hline$t+90$ & $0.74 \pm 0.31$ & $0.66 \pm 0.24$ \\
\hline$t+120$ & $0.58 \pm 0.24$ & $0.66 \pm 0.24$ \\
\hline $\begin{array}{c}\text { Plasma aldosterone } \\
\text { (pmol/l) }\end{array}$ & PRE pioglitazone & POST pioglitazone \\
\hline $\mathbf{t}+\mathbf{0}$ & $1600 \pm 262$ & $1029 \pm 216$ \\
\hline$t+30$ & $988 \pm 119^{\infty}$ & $707 \pm 97^{*}$ \\
\hline$t+60$ & $705 \pm 63^{\infty}$ & $560 \pm 59^{* \infty}$ \\
\hline$t+90$ & $571 \pm 48^{\infty}$ & $491 \pm 45^{*_{\infty}}$ \\
\hline$t+120$ & $504 \pm 36^{\infty}$ & $460 \pm 29^{*_{\infty}}$ \\
\hline $\begin{array}{c}\text { Plasma vasopressin } \\
\text { (pmol/l) }\end{array}$ & PRE pioglitazone & POST pioglitazone \\
\hline $\mathbf{t}+\mathbf{0}$ & $1.11 \pm 0.11$ & $0.93 \pm 0.09$ \\
\hline$t+30$ & $0.88 \pm 0.05^{\infty}$ & $0.89 \pm 0.05$ \\
\hline$t+60$ & $0.82 \pm 0.06^{\infty}$ & $0.85 \pm 0.07$ \\
\hline$t+90$ & $0.79 \pm 0.05^{\infty}$ & $0.78 \pm 0.05^{\infty}$ \\
\hline$t+120$ & $0.78 \pm 0.05^{\infty}$ & $0.77 \pm 0.06^{\infty}$ \\
\hline
\end{tabular}

${ }^{*} \mathrm{p}<0.05$ vs pre; ${ }^{\infty} \mathrm{p}<0.05$ vs $\mathrm{t}+0$. 
Table 3. Plasma cathecolamins during volume expansion before and after therapy.

\begin{tabular}{ccc}
\hline $\begin{array}{c}\text { Plasma epinephrine } \\
\text { (pg/ml) }\end{array}$ & PRE pioglitazone & $\begin{array}{c}\text { POST pioglita- } \\
\text { zone }\end{array}$ \\
\hline $\mathbf{t}+\mathbf{0}$ & $129.4 \pm 21.3$ & $163.7 \pm 27.9$ \\
$\mathbf{t}+\mathbf{3 0}$ & $90.1 \pm 3.6$ & $116.2 \pm 38.7$ \\
$\mathbf{t}+\mathbf{6 0}$ & $86.2 \pm 3.8$ & $129.9 \pm 32.5$ \\
$\mathbf{t}+\mathbf{9 0}$ & $105 \pm 3.7$ & $123.3 \pm 35.9$ \\
$\mathbf{t}+\mathbf{1 2 0}$ & $90.6 \pm 19.1$ & $159.9 \pm 26.2^{*}$ \\
Plasma norepinephrine & PRE pioglitazone & POST pioglita- \\
$\mathbf{( n m o l / l )}$ & $0.14 \pm 0.02$ & $0.18 \pm 0.3$ \\
$\mathbf{t}+\mathbf{0}$ & $0.10 \pm 0.01$ & $0.13 \pm 0.2$ \\
$\mathbf{t}+\mathbf{3 0}$ & $0.09 \pm 0.02$ & $0.14 \pm 0.4$ \\
$\mathbf{t}+\mathbf{6 0}$ & $0.11 \pm 0.02$ & $0.13 \pm 0.4$ \\
$\mathbf{t}+\mathbf{9 0}$ & $0.10 \pm 0.2$ & $0.17 \pm 0.3^{*}$ \\
$\mathbf{t + 1 2 0}$ & & \\
\hline
\end{tabular}

${ }^{*} \mathrm{p}<0.05$ vs pre

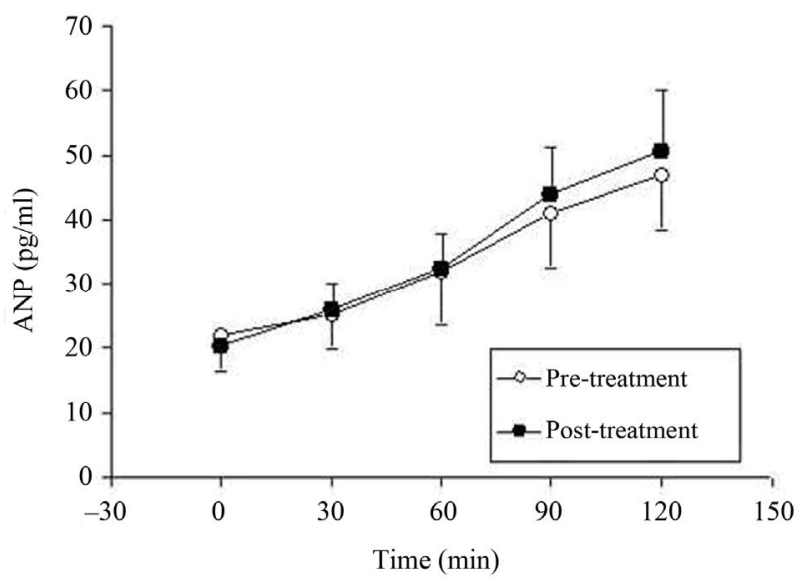

Figure 1. Increase of atrial natriuretic peptide during volume expansion before and after pioglitazone treatment in diabetic patients.

\section{DISCUSSION}

In the present work we studied the circulating ANP responses to an isotonic blood volume expansion after one month of pioglitazone therapy in 12 T2DP. Data from recent large-scale clinical trials [26] raised particular concerns in regard to the use of thiazolidinediones that appear to increase the risk of heart failure in T2DP. Nonetheless and particularly, pioglitazone therapy has also been associated with a significantly lower risk of sudden death, myocardial infarction, or stroke among different populations of patients with diabetes as indicated by a recent meta-analysis [27]. It was also verified that, in large clinical studies, the occurrence of edema with thiazolidinediones was not associated with an increase in heart failure events [28].
The use of thiazolidinediones can be very useful in the treatment of type 2 diabetes mellitus and particularly by decreasing cardiovascular risk [29-32]. Therefore the significant sodium retention in a subpopulation of patients with serious alteration of salt/water homeostasis could be an important limitation as to the use of this class of drugs.

In our study the reduction of hematocrit and relative dilution of blood cell counts after one month of pioglitazone treatment seem to support the sodium retention induced by TZD.

The ANP plasma level is an important marker to identify patients at high risk for of heart failure and, in general, other natriuretic peptides (like the amino terminus of Atrial Natriuretic Peptide, the Brain Natriuretic Peptide, and the amino terminus of Brain Natriuretic Peptide) were even better markers for two and three-year followup outcome in mild and moderate chronic heart failurepatients $[20,33]$.

In humans, the physiological ANP secretion by myocardiocytes of the right atrium is regulated by a variation of the venous return and consequently by a change of the intra-atrial pressure. Only partially ANP secretion is regulated by plasma osmolality [34].

We recently demonstrated that after acute insulin stimulation, the plasma concentration of ANP increased similarly in four groups: T2DP patients (without heart transplantation as control), healthy subjects as controls, and in diabetic and nondiabetic heart-transplanted patients; the four groups of subjects investigated were homogenous for age, similar time elapsed from transplant, good general conditions, and normal hemodynamic profiles. No differences parameters were also noted for plasma catecholamine concentration and osmolality [12]. Therefore the presence of chronic hyperglycemia emerged as the major factor responsible for the higher plasma ANP concentrations measured in transplant recipients with glucose intolerance or overt diabetes.

The present results show that subjects with diabetes prior or after pioglitazone therapy have the similar response of ANP plasma concentration to volume expansion. These patients, after therapy, have expanded the circulating volume, as demonstrated by the hematocrit decrease and by plasma aldosterone levels.

Interestingly similar basal and after saline infusion ANP plasma levels were ascertained before and after the pioglitazone therapy, independently of the expanded volume triggered by the treatment. The present results have a strong clinical impact: 1) It is clear that ANP concentration could not be used as a marker of subclinical heart failure in diabetic patients treated or not with pioglitazone; 2) Type 2 diabetic patients even if in stable metabolic conditions have a severe alteration of ANP secretion/degradation in response to a physiological sti- 
mulus (circulating volume expansion), independently of sympathetic innervation; 3) Such impaired ANP plasma level regulation in type 2 diabetes is not reverted by one month of pioglitazone therapy, even if the metabolic and clinical profile is significantly improved (i.e. lipid-, glucose profile, and blood pressure).

The alteration of ANP plasma concentration during diabetes mellitus has not an univocal explanation. First, heart denervation or partial reinnervation may not have a role in the regulation of ANP balance [8,9]. Therefore a partial defect of sympathetic system is not relevant in the regulation of ANP plasma concentration, while chronic hyperglycemia (in type 2 diabetic patients with and without transplantation) induces elevated levels of plasma ANP levels regardless of chronic hyperinsulinemia. Second, Zanchi and colleagues [23] showed in healthy subjects no changes in ANP values with pioglitazone treatment and the authors suggested a certain degree of peripheral vasodilatation along with volume redistribution as possible causes of fluid retention rather than ANP. Third, studies in animal models showed that treatment with a TZD (rosiglitazone) induced cardiac hypertrophy in both cardiomyocyte-specific PPAR-knockout mice and in the littermate controls. These transgenic mice were found to have increased expression of cardiac embryonic genes (atrial natriuretic peptide) [20]. Sechi and colleagues pointed out that the decreased number of biologically active ANP receptors in the kidneys of diabetic rats is coupled to an overall decreased biological responsiveness in vitro, and that provides a potential explanation for the reduction in renal sensitivity to ANP in the diabetic condition [18].

Our data seem to be in contrast with results found in a recent publication [35] showing that in type 2 diabetic subjects the impairment of ANP response to immersion was restored by rosiglitazone (after they had taken $4 \mathrm{mg}$ of rosiglitazone every morning for 7 days prior to the study). However, the different type of TZD and the particular stimulus to cause volume expansion head-out water immersion) could explain the differences found in that study.

Since the increased levels of plasma ANP concentrations represent a noted predictor of worsening of the cardiac pump failure in patients with diabetes, our results suggest that ANP may be involved in the pathogenesis of cardiomyopathy and heart failure in diabetic recipients during TZD treatment. In conclusion, plasma ANP response to plasma volume expansion is completely altered in T2DP and one month of pioglitazone therapy is not able to revert this condition.

\section{REFERENCES}

[1] Salazar, F.J., Granger, J.P., Joyce, M.L.M., Burnett, J.C.,
Bove Jr., A.A. and Romero, J.C. (1986) Effects of hypertonic saline infusion and water drinking on atrial peptide. American Journal of Physiology, 251, R1091-R1094.

[2] Laine, M., Arajama, O., Voulteenaho, O., Ruskoaho, H. and Weckstrom, M. (1994) Block of stretch-activated atrial natriuretic peptide secretion by gadolinium in isolated rat atrium. The Journal of Physiology, 480, 553-561.

[3] Clark, B.A., Sclater, A., Epstein, F.H. and Elahi, D. (1993) Effect of glucose, insulin, and hypertonicity on atrial natriuretic peptide levels in man. Metabolism, 42, 224-228. doi:10.1016/0026-0495(93)90040-U

[4] Ohno, Y., Suzuki, H., Yamakawa, H., Nakamura, M., Kato, Y. and Saruta, T. (2001) Correlation of sodium-related factors with insulin sensitivity in young, lean, male offspring of hypertensive and normotensive subjects. Journal of Human Hypertension, 15, 393-399. doi:10.1038/sj.jhh.1001211

[5] Tanabe, A., Naruse, M., Wasada, T., Naruse, K., Yoshimoto, T., Omori, Y. and Demura, H. (1995) Effects of acute hyperinsulinemia on plasma atrial and brain natriuretic peptide concentrations. European Journal of Endocrinology, 132, 693-698. doi:10.1530/eje.0.1320693

[6] Bohlen, L., Ferrari, P., Papiri, M., Allemann, Y., Shaw, S. and Wiedmann, P. (1994) Atrial natriuretic factor increases in response to an acute glucose load. Journal of Human Hypertension, 12, 803-807.

[7] Reddy, S., Kelly, D., Cocineas, C. and Gyory, Z. (1988) Additive and synergistic interaction of atrial natriuretic peptide and volume expansion. American Journal of Physiology, 255, F66-F73.

[8] Ationu, A., Burch, M., Singer, D., Littleton, P. and Carter, N. (1993) Cardiac transplantation affects ventricular expression of brain natriuretic peptide. Cardiovascular Research, 27, 188-191. doi:10.1093/cvr/27.2.188

[9] Geny, B., Piquard, F., Follenius, M., Thiranos, J.C., Charpentier, A., Epailly, E., Levy, F., Kretz, J.G., Eisenmann, B. and Haberey, P. (1998) Endothelin participates in increased circulating atrial natriuretic peptide early after human heart transplantation. The Journal of Heart and Lung Transplantation, 17, 167-175.

[10] Weston, M.W., Cintron, G.B., Giordano, A.T. and Vesely, D.L. (1994) Normalisation of circulating atrial natriuretic peptides in cardiac transplant recipients. American Heart Journal, 127, 129-142. doi:10.1016/0002-8703(94)90518-5

[11] Starling, R.C., O’Dorisio, T.M., Malarkey, W.B., Murray, K.D., Myerowitz, P.D. and Cody, R.J. (1991) Preserved atrial natriuretic peptide secretory function after cardiac transplantation. American Journal of Cardiology, 68, 237241.

[12] Benedini, S., Fiocchi, R., Battezzati, A., et al. (2007) Atrial natriuretic peptide in diabetic and nondiabetic patients with and without heart transplantation. Transplantation Proceedings, 39, 1580-1585. doi:10.1016/j.transproceed.2007.04.020

[13] Patel, K.P. (1997) Volume reflex in diabetes. Cardiovascular Research, 34, 81-90. doi:10.1016/S0008-6363(97)00012-6 
[14] Oliveira, V.L., Moreira, E.D., Farah, V.M., et al. (1999) Cardiopulmonary reflex impairment in experimental diabetes in rats. Hypertension, 34, 813-817. doi:10.1161/01.HYP.34.4.813

[15] Beretta-Piccoli, C., Elshater-Zanetti, F., Shaw, S., et al. (1994) Acute sodium loading in patients with uncomplicated diabetes mellitus: Renal and hormonal effects. Clinical Science, 86, 383-390

[16] Salas-Ramirez, M., Ariza Andraca, R., Frati Munari, A., et al. (1995) Effect of plasma volume expansion on auricular natriuretic peptide in non-dependent insulin diabetic patients with autonomic neuropathy. Archives of $\mathrm{Me}$ dical Research, 26, 35-40.

[17] Trevisan, R., Fioretto, P., Semplicini, A., et al. (1990) Role of insulin and atrial natriuretic peptide in sodium retention in insulin-treated IDDM patients during isotonic volume expansion. Diabetes, 39, 289-298. doi:10.2337/diabetes.39.3.289

[18] Sechi, L., Valentin, J.P., Griffin, C.A., et al. (1995) Receptors for atrial natriuretic peptide are decreased in the kidney of rats with streptozocin-induced diabetes mellitus. The Journal of Clinical Investigation, 95, 2451-2457. doi:10.1172/JCI117945

[19] Asakawa, M., Takano, H., Nagai, T., et al. (2002) Peroxi- some proliferator-activated receptor-gamma plays a cri- tical role in inhibition of cardiac hypertrophy in vitro and in vivo. Circulation, 105, 1240-1246. doi:10.1161/hc1002.105225

[20] Duan, S.Z., Ivashchenko, C.Y., Russel, M.W., et al. (2005) Cardiomyocyte-specific knockout and agonist of peroxisome proliferators-activated receptor-gamma both induce cardiac hypertrophy in mice. Circulation Research, 97, 372379. doi:10.1161/01.RES.0000179226.34112.6d

[21] Waugh, J., Keating, G.M., Plosker, G.L., Easthope, S. and Robinson, D.M. (2006) Pioglitazone: A review of its use in type 2 diabetes mellitus. Drugs, 66, 85-109. doi:10.2165/00003495-200666010-00005

[22] Rennings, A.J., Smits, P., Stewart, M.W., et al. (2006) Fluid retention and vascular effects of rosiglitazone in obese, insulin-resistant, nondiabetic subjects. Diabetes Care, 29, 581-587. doi:10.2337/diacare.29.03.06.dc05-01467

[23] Zanchi, A., Chiolero, A., Maillard, M., et al. (2004) Effects of the peroxisome proliferators-activated receptorgamma agonist Pioglitazone on renal and hormonal responses to salt in healty men. The Journal of Clinical Endocrinology \& Metabolism, 89, 1140-1145. doi:10.1210/jc.2003-031526

[24] Decaux, G., Dumont, I., Naeije, N., et al. (1982) High uric acid clearance in cirrhosis secondary to increased "effective vascular volume". American Journal of Medicine, 73, 328-334. doi:10.1016/0002-9343(82)90718-5

[25] Weinman, E.J., Eknoyan, G. and Suki, W.N. (1975) The influence of the extracellular fluid volume on the tubular reabsorption of uric acid. Journal of Clinical Investigation, 55, 283-291. doi:10.1172/JCI107931

[26] Nesto, R.W., Bell, D., Bonow, R.O., Fonseca, V., Grun- dy, S.M., Horton, E.S., et al. (2003) Thiazolidinedione use, fluid retention, and congestive heart failure: A consensus statement from the American Heart Association and American Diabetes Association. Circulation, 108, 2941-2948.

[27] Lincoff, A.M., Wolski, K., Nicholls, S.J. and Nissen, S.E. (2007) Pioglitazone and risk of cardiovascular events in patients with type 2 diabetes mellitus: A meta-analysis of randomized trials. JAMA, 298, 1180-1188.

[28] Erdmann, E. and Wilcox, R.G. (2008) Weighing up the cardiovascular benefits of thiazolidinedione therapy: The impact of increased risk of heart failure. European Heart Journal, 29, 12-20. doi:10.1093/eurheartj/ehm529

[29] Schernthaner, G., Matthews, D.R., Charbonnel, B., et al. (2004) Efficacy and safety of pioglitazone versus metformin in patients with type 2 diabetes mellitus: a double- blind, randomized trial. The Journal of Clinical Endocrinology \& Metabolism, 89, 6068-6076. doi:10.1210/jc.2003-030861

[30] St. John Sutton, M., Rendell, M., Dandona, P., et al. (2002) A comparison of the effects of rosiglitazone and glyburide on cardiovascular function and glycemic control in patients with type 2 diabetes. Diabetes Care, 25, 20582064. doi:10.2337/diacare.25.11.2058

[31] Goldberg, R.B., Kendall, D.M., Deeg, M.A., et al. (2005) A comparison of lipid and glycemic effects of pioglitazone and rosiglitazone in patients with type 2 diabetes and dyslipidemia. Diabetes Care, 28, 1547-1554. doi:10.2337/diacare.28.7.1547

[32] Dormandy, J.A., Charbonnel, B., Eckland, D.J., Erdmann, E., Massi-Benedetti, M., Moules, I.K., Skene, A.M., Tan, M.H., Lefèbvre, P.J., Murray, G.D., Standl, E., Wilcox, R.G., Wilhelmsen, L., Betteridge, J., Birkeland, K., Golay, A., Heine, R.J., Korányi, L., Laakso, M., Mokán, M., Norkus, A., Pirags, V., Podar, T., Scheen, A., Scherbaum, W., Schernthaner, G., Schmitz, O., Skrha, J., Smith, U. and Taton, J., (2005) PROactive investigators. Secondary prevention of macrovascular events in patients with type 2 diabetes in the PROactive Study (PROspective pioglitAzone Clinical Trial in macroVascular Events): A randomised controlled trial. Lancet, 366, 1279-1289. doi:10.1016/S0140-6736(05)67528-9

[33] Berger, R., Strecker, K., Huelsmann, M., Moser, P., Frey, B., Bojic, A., Stanek, B. and Pacher, R. (2003) Prognostic power of neurohumoral parameters in chronic heart failure depends on clinical stage and observation period. The Journal of Heart and Lung Transplantation, 22, 1037- 1045. doi:10.1016/S1053-2498(02)00560-0

[34] Ballerman, B.J., Brenner, B.M. and George, E. (1986) Brown memorial lecture. Role of atrial peptides in body fluid homeostasis. Circulation Research, 58, 619-630. doi:10.1161/01.RES.58.5.619

[35] Goenka, N., Kotonya, C., Penney, M.D., Randeva, H.S. and O'Hare, J.P. (2008) Thiazolidinediones and the renal and hormonal response to water immersion-induced volume expansion in type 2 diabetes mellitus. American Journal of Physiology-Endocrinology and Metabolism, 294, 733-739. doi:10.1152/ajpendo.00583.2007 